\title{
The time variation of dose rate artificially increased by the Fukushima nuclear crisis
}

SUBJECT AREAS:

ENVIRONMENTAL

SCIENCES

EARTH SCIENCES

APPLIED PHYSICS

NUCLEAR PHYSICS

Received

27 June 2011

Accepted

22 August 2011

Published

7 September 2011

Correspondence and requests for materials should be addressed to

S.T. (tokonami@cc.

hirosaki-u.ac.jp)
Masahiro Hosoda' , Shinii Tokonami ${ }^{2}$, Atsuyuki Sorimachi ${ }^{2}$, Satoru Monzen' ${ }^{1}$ Minoru Osanai ${ }^{1}$, Masatoshi Yamada ${ }^{2}$, Ikuo Kashiwakura' \& Suminori Akiba ${ }^{3}$

${ }^{1}$ Hirosaki University, Graduate School of Health Sciences, 66-1 Hon-cho, Hirosaki, Aomori 036-8564, Japan, ${ }^{2}$ Hirosaki University, Institute of Radiation Emergency Medicine, 66-1 Hon-cho, Hirosaki, Aomori 036-8564, Japan, ${ }^{3}$ Kagoshima University, Graduate School of Medical and Dental Sciences, 8-35-1 Sakuragaoka, Kagoshima 890-8544, Japan.

A car-borne survey for dose rate in air was carried out in March and April 2011 along an expressway passing northwest of the Fukushima Dai-ichi Nuclear Power Station which released radionuclides starting after the Great East Japan Earthquake on March 11, 2011, and in an area closer to the Fukushima NPS which is known to have been strongly affected. Dose rates along the expressway, i.e. relatively far from the power station were higher after than before March 11, in some places by several orders of magnitude, implying that there were some additional releases from Fukushima NPS. The maximum dose rate in air within the high level contamination area was $36 \mu \mathrm{Gy} \mathrm{h}{ }^{-1}$, and the estimated maximum cumulative external dose for evacuees who came from Namie Town to evacuation sites (e.g. Fukushima, Koriyama and Nihonmatsu Cities) was $68 \mathrm{mSv}$. The evacuation is justified from the viewpoint of radiation protection.

t 2:46 pm (JST) on March 11, 2011, Japan experienced one of the most powerful earthquakes $(\mathrm{M}=9.0)$ in recorded history, now known as "the Great East Japan Earthquake"1,2. The power supply for cooling in the Fukushima Dai-ichi Nuclear Power Station (Fukushima NPS) was stopped under the influence of tsunami generated by this earthquake ${ }^{3}$. Hydrogen explosions at Units 1, 3 and 2 occurred at 3:36 pm on March 12, at 11:01 am on March 14, and at 6:14 am on March 15, respectively. Artificial radionuclides such as xenon-133, iodine-131, cesium-134, and cesium-137 were released from the reactor buildings into the environment ${ }^{4}$. These radionuclides were observed not only in $\mathrm{Japan}^{5}$ but also in the northwestern United States ${ }^{6}$ and all over Europe (e.g. for Northern Greece, see ref. 7). The nuclear crisis has not ended yet, and dose estimations for workers and residents, and environmental assessment are still only preliminary. In the present study, effects on the living environment by artificial radionuclides released by the Fukushima NPS crisis were estimated. Dose rates in air along an expressway passing northwest of the Fukushima NPS were measured in a car-borne survey, and temporal variation of dose rate in air is discussed. A car-borne survey in a high level contamination area was also carried out for an external dose estimation for the persons who lived in this area but were evacuated as the crisis developed.

\section{Results}

Temporal variation of dose rate in air by car-borne survey along an expressway. The results of temporal variation of dose rate in air measured in the car-borne survey along the expressway are shown in Figure 1. Since dose rate was measured inside the car, it was corrected by multiplying with a shielding factor in order to represent unshielded external dose rate. The dose rates in air before the start of the nuclear crisis are also shown for data reported by Minato ${ }^{8}$ and for data measured by one of the authors on August 2, 2010. Although the measurement methods differed, the values before March 11 were in good agreement. Therefore, these values were deemed suitable as representing the background dose rate level before the accident. In detail, the results are:

(1) In the first survey (March 16), the dose rates along the expressway between Fukushima City $\left(37.72^{\circ} \mathrm{N}\right.$, $140.44^{\circ} \mathrm{E} ; 60 \mathrm{~km}$ from the Fukushima NPS) and about Osaki City $\left(39.07^{\circ} \mathrm{N}, 141.10^{\circ} \mathrm{E} ; 140 \mathrm{~km}\right.$ from the Fukushima NPS) were found to have increased strongly, from about 0.08 to up to $11 \mu \mathrm{Gy} \mathrm{h}$.

(2) In the remaining part of the transect the dose rates increased little, by a factor about 1.5 to 2.5, or not at all, as found further away in Aomori Prefecture, more than $300 \mathrm{~km}$ from the Fukushima NPS.

(3) The dose rate profile along the transect looked quite differently in the second and third survey, $11^{\text {th }}$ and $25^{\text {th }}$ April, i.e. about one month after the first one. In the part of the transect which is closer to the Fukushima NPS, between Fukushima City and about Sendai City $\left(38.36^{\circ} \mathrm{N}, 140.88^{\circ} \mathrm{E}\right.$; ca. $100 \mathrm{~km}$ from 

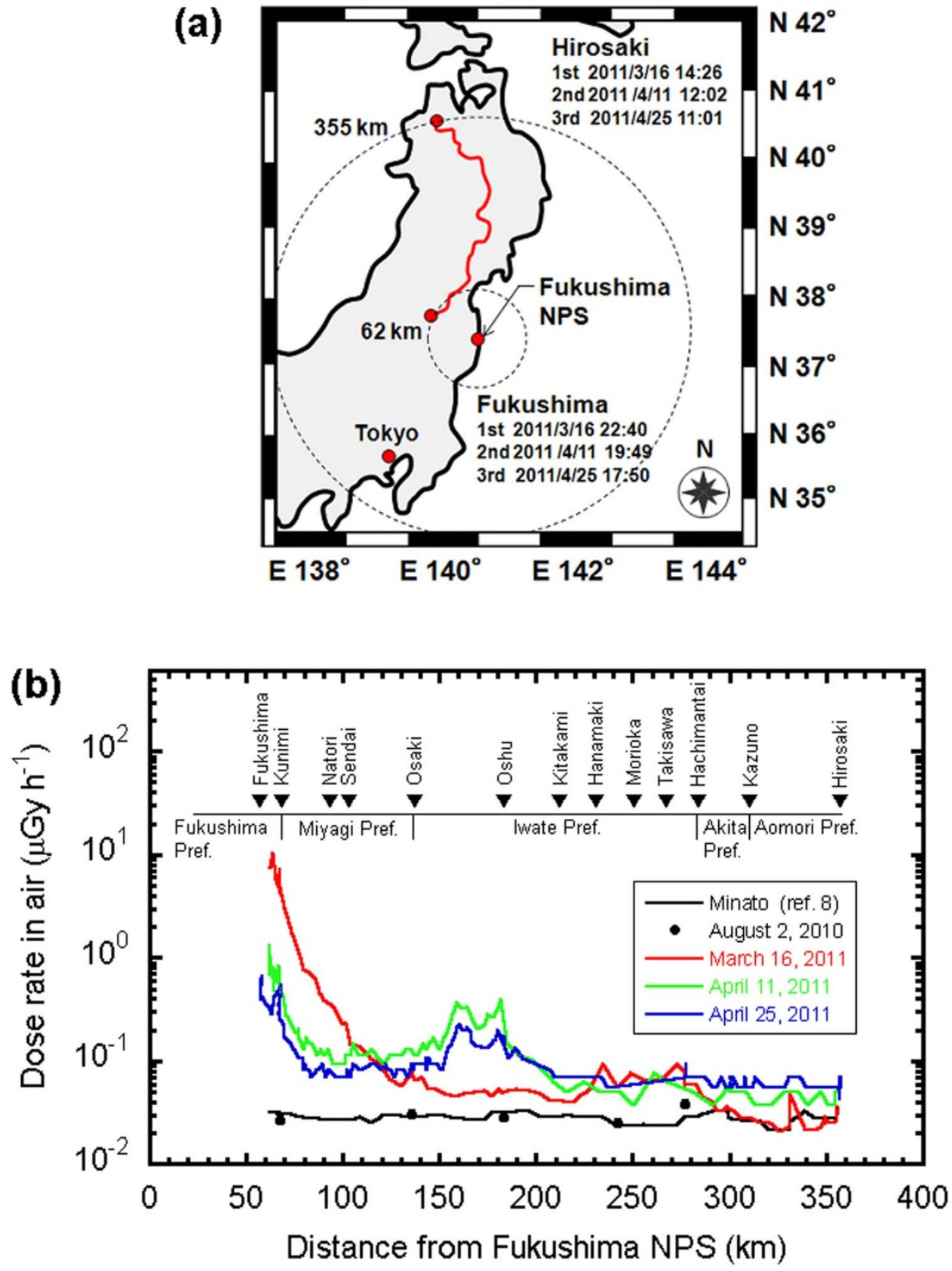

Figure 1 (a) Expressway survey route for measuring dose rates in air from Hirosaki City to Fukushima City. The starting point on March 16 and April 11 was Hirosaki City and on April 25 it was Fukushima City. Total distance on the expressway was $1256 \mathrm{~km}$. (b) Temporal variation of dose rates in air before and after the start of the Fukushima NPS crisis. The black line shows the dose rate in air reported by Minato ${ }^{8}$ in 2006 . The solid black symbols are dose rates in air measured on August 2, 2010. The red, green and blue lines are dose rates in air measured on March 16, April 11 and April 25, 2011, respectively.

the Fukushima NPS) the dose rate decreased by a factor 1 to 2 in Sendai City, up to a factor greater than 10 in Fukushima City. The effective half life estimated from the readings at the nearest measurement point to the Fukushima NPS was close to the physical half life of iodine-131 (8 days).

(4) Contrary to this tendency, the dose rate increased in the remaining part of the transect, starting from about Sendai City until Aomori Prefecture. (It remained about equal in the section ca. $230-280 \mathrm{~km}$ from the Fukushima NPS.) The effect is particularly striking around Oshu City $\left(39.07^{\circ} \mathrm{N}, 141.10^{\circ} \mathrm{E}\right.$; ca. $180 \mathrm{~km}$ from the Fukushima NPS), where the dose rate increased by a factor up to 10 between the first and the second survey.
Comparison of measured dose rates in air on pavement and unsealed surfaces. A comparison of measured dose rates in air on pavement and unsealed surfaces is shown in Figure 2. The dose rates on the unsealed surfaces were from 1.0 to 2.1 times (average: 1.3 times, $n=20$ ) higher than those on pavement.

External dose estimation within the high level contamination area. The survey route within the high level contamination area and a distribution map of dose rate in air are shown in Figure 3. The map has been drawn based on the 1623 measurements obtained during the survey. The dose rates in air did not depend on the distance from the Fukushima NPS and the most contaminated area was to its northwest (Namie Town and Iitate Village). 


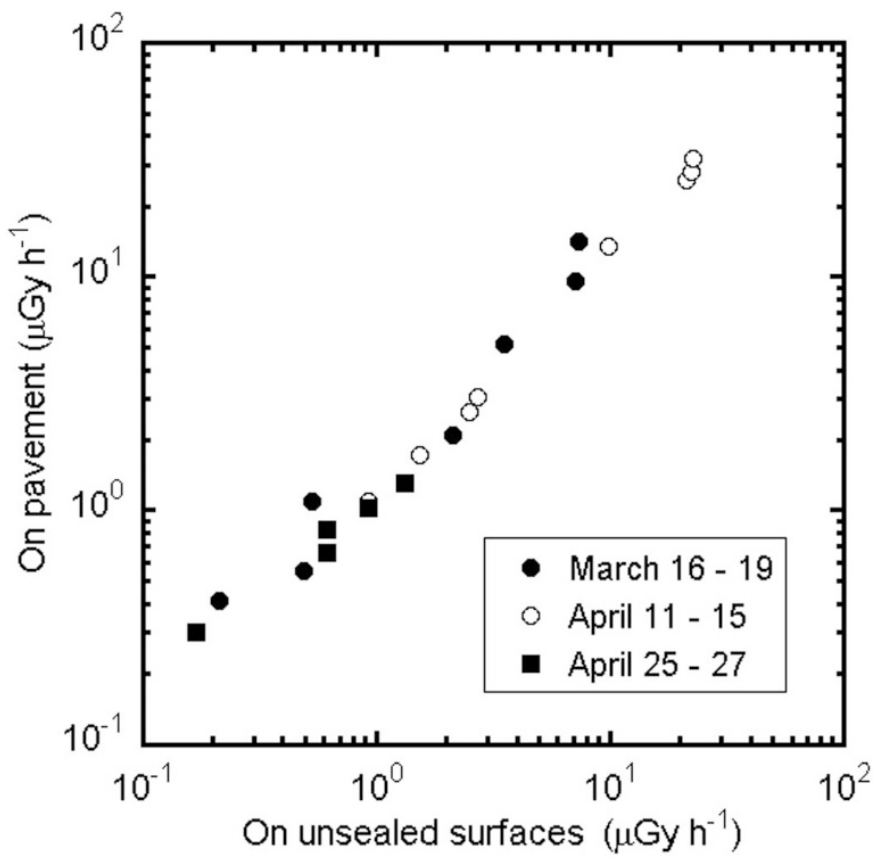

Figure 2 Comparison of measured dose rates in air on pavement and uncovered surfaces.

Although measurement techniques were different, our result shows a similar distribution to the map reported by the Ministry of Education, Culture, Sports, Science and Technology, Japan (MEXT) and the United States Department of Energy (U. S. DOE) ${ }^{9}$. The highest observed dose rate in air was $36 \mu \mathrm{Gy} \mathrm{h}^{-1}(5: 08 \mathrm{pm}$, April 12, 2011) at Hirusone, Namie Town $\left(37.55^{\circ} \mathrm{N}, 140.84^{\circ} \mathrm{E}\right)$.

In-situ gamma spectra. The in-situ gamma spectra obtained at Kunimi Town $\left(37.91^{\circ} \mathrm{N}, 140.58^{\circ} \mathrm{E}\right)$ and Oshu City are shown in Figure 4. Photon peaks generated by tellurium-132, iodine-131, -132, and cesium-134, -136 and -137 were observed in the spectra on March 19 at both measurement points. On the other hand, no photon peaks generated by tellurium-132 (3.2 d), iodine-131 $(8.0 \mathrm{~d})$ and iodine-132 $(2.3 \mathrm{~h})$, all short half life nuclides, were observed in the spectra on April 25. This can be explained by radioactive decay which amounts to a factor about 25 for iodine131, between 19 March and 25 April. While in Kunimi Town the

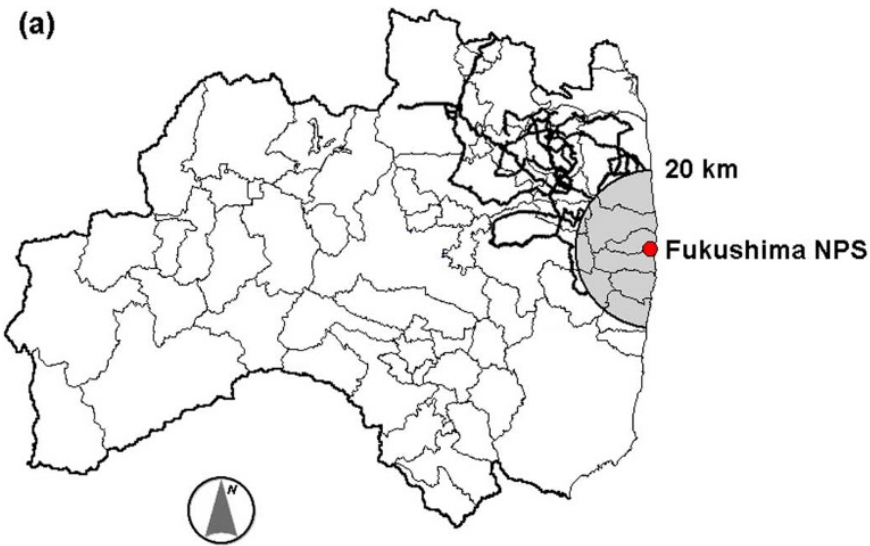

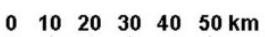

dose rates due to radiocesium decreased from March to April (the nuclide-specific dose rate is proportional to the gamma peak area), it has increased further away in Oshu City. This confirms the finding (4) from the dose rate survey along the expressway: the observed increase in dose rate, in particular around Oshu City, appears to have been caused by additional input of radiocaesium.

\section{Discussion}

Two assumptions were considered to explain the results (Figure 1) of dose rates in air observed from Kitakami City to Sendai City on April 11. (1) The artificial radionuclides were released from the Fukushima NPS to the environment continuously. (2) Passing vehicles dispersed the contamination along the roads.

It was clear from Figure 4(b) that the counts of cesium-134 and -137 on April 25 were much higher than those on March 19. This implies that there were some additional releases from Fukushima NPS. If the contamination was dispersed by passing vehicles along the roads, the dose rate would increase from Sendai City. Therefore the second assumption was rejected. The dose rates in air from cesium-134 and -137 were calculated using analysis software developed by Minato ${ }^{10}$. The dose rates in air from cesium-134 and -137 on March 19 were $0.009 \mu \mathrm{Gy} \mathrm{h} \mathrm{h}^{-1}$ and $0.002 \mu \mathrm{Gy} \mathrm{h}{ }^{-1}$, respectively. On the other hand, these values on April 25 were estimated to be $0.097 \mu \mathrm{Gy} \mathrm{h} \mathrm{h}^{-1}$ and $0.023 \mu \mathrm{Gy} \mathrm{h} \mathrm{h}^{-1}$, respectively, and quite different from the values of March 19.

The observation of lower dose rate over sealed surfaces can be explained by easier removal of deposited radionuclides from sealed surfaces, like pavement of concrete or asphalt. Contamination can be washed away more easily by rain, and also resuspension by wind is easier from sealed than from unsealed surfaces, where the contamination adheres to soil particles and plants ${ }^{11-14}$.

The cumulative external dose was estimated using measured values from Hirusone, Namie Town which were the maximum in this survey. The cumulative external dose for a one year period at Hirusone from March 12, 2011 to March 11, 2012 was estimated by MEXT based on actual measurement data to June 11, 2011 (the data can be found on the MEXT website ${ }^{9}$ ). The value estimated by MEXT is $217.7 \mathrm{mSv}$. In the present study, the monitoring data measured by Fukushima Prefecture were used for calculation of cumulative external dose from March 12, 2011 to the authors' measurement date $^{15}$. Some assumptions were considered for the estimation of cumulative external dose from March 12, 2011 to March 11, 2012. (1) The temporal variation of dose rate in air between Hirusone, Namie Town and the MEXT monitoring station at Iitate Village

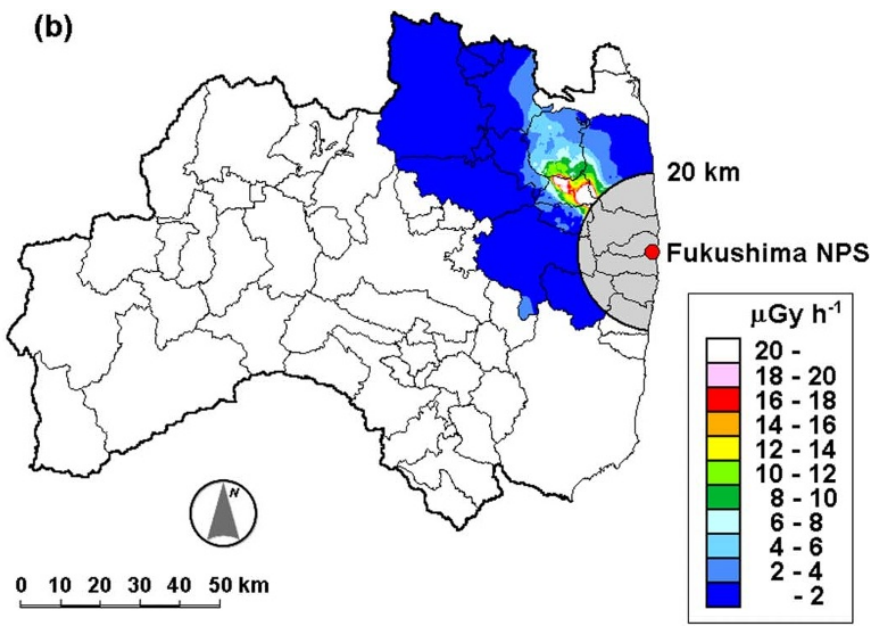

Figure 3 (a) Survey route for measuring dose rates in air within the high level contamination area. Total distance for the car-borne survey in this area was $730 \mathrm{~km}$. (b) Distribution map of the dose rates in air within the high level contamination area in Fukushima Prefecture. The rates were classified into eleven groups from $<2 \mu \mathrm{Gy} \mathrm{h} \mathrm{h}^{-1}$ to $>20 \mu \mathrm{Gy} \mathrm{h} \mathrm{h}^{-1}$ at intervals of $2 \mu \mathrm{Gy} \mathrm{h} \mathrm{h}^{-1}$. 

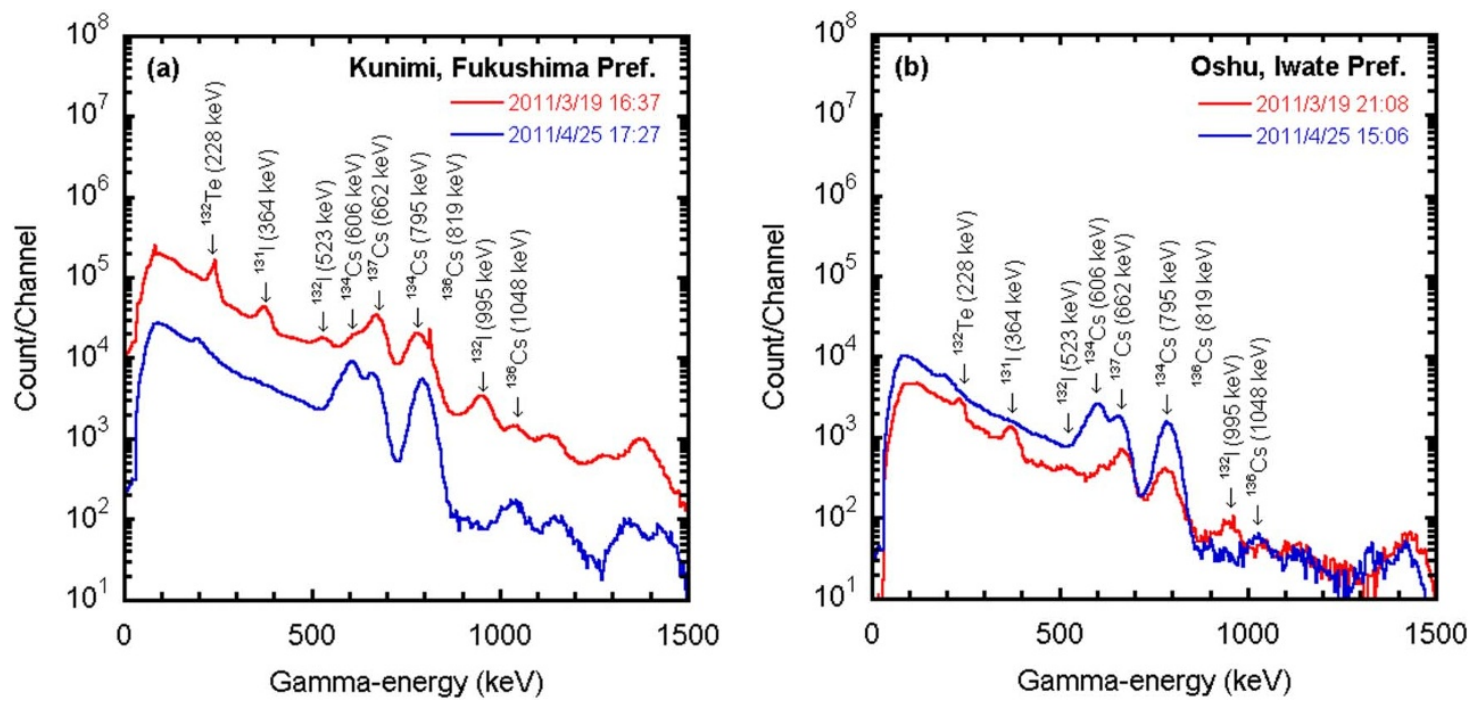

Figure $4 \mid$ Temporal variation of in-situ gamma spectra measured at Kunimi, Fukushima Prefecture (a) and Oshu, Iwate Prefecture (b).

$\left(37.68^{\circ} \mathrm{N}, 140.74^{\circ} \mathrm{E}\right)$ was the same. (2) The dose rates in air at Hirusone were proportional to the values of Iitate Village. (3) The missing monitoring data from March 12 to 14 were of same level as the dose rate before rainfall at 2:00 pm on March 14. (4) The contribution by cesium-134 and -137 to the dose rates were estimated using a $3^{\prime \prime} \times 3^{\prime \prime} \mathrm{NaI}(\mathrm{Tl})$ scintillation spectrometer in Namie Town, and these values were set as 0.75 and 0.25 , respectively. (5) Decrease of dose rate due to physical decay of cesium-134 and -137 was considered. (6) The conversion factor from pavement to soil was set to 1.3. (7) The indoor and outdoor dwelling times were set as 16 hours and 8 hours, respectively, and the shielding coefficient by walls was set as 0.4 , the same values as used by MEXT. The cumulative external dose was estimated to be $194 \mathrm{mSv}$ and was close to the value presented by MEXT (217.7 mSv).

The maximum value of a residential area was $32 \mu \mathrm{Gy} \mathrm{h} \mathrm{h}^{-1}$ at 1:12 pm on April 15 at Koakuto, Namie Town $\left(37.58^{\circ} \mathrm{N}\right.$, $\left.140.77^{\circ} \mathrm{E}\right)$. The dose estimation was then carried out for evacuees who were living in this area until May 10, 2011. This result included the assumption that the evacuees lived in Fukushima City $\left(0.27-3.2 \mu \mathrm{Gy} \mathrm{h}^{-1}\right)$, Koriyama City $\left(0.45-0.91 \mu \mathrm{Gy} \mathrm{h} \mathrm{h}^{-1}\right)$ and Nihonmatsu City $\left(0.77-2.2 \mu \mathrm{Gy} \mathrm{h}^{-1}\right)$ from May 11, 2011 to March 11, 2012, where the range of the dose rate in air was based on the measurement data from April 12 to 15 (except for Koriyama City for which data collected on April 25 were used). The cumulative external doses for evacuees to Fukushima, Koriyama and Nihonmatsu Cities were estimated to be $57-68 \mathrm{mSv}, 57-59 \mathrm{mSv}$ and $59-64 \mathrm{mSv}$, respectively. The evacuation is justified from the viewpoint of radiation protection.

\section{Methods}

Measurement technique of car-borne survey along an expressway. The measurements of dose rates in air from fallout were carried out along the expressway from Hirosaki City $\left(40.59^{\circ} \mathrm{N}, 140.47^{\circ} \mathrm{E}\right)$ to Fukushima City $\left(37.75^{\circ} \mathrm{N}, 140.30^{\circ} \mathrm{E}\right)$ (Figure 1). A car-borne survey technique using a $1^{\prime \prime} \times 1^{\prime \prime} \mathrm{NaI}(\mathrm{Tl})$ scintillation survey meter (TCS-171, ALOKA Co., Japan) was employed. Measurements were carried out every one minute. This survey meter was calibrated with a $2^{\prime \prime} \times 2^{\prime \prime} \mathrm{NaI}(\mathrm{Tl})$ scintillation spectrometer (SPA-3, Eberline Co., U.S.A). The reported values represent air kerma rate. Latitude and longitude at each measurement point were measured with a global positioning system (WPL-2000, Wintec Co., Ltd., Taiwan) at the same time as the survey measurements were made. The car-borne survey technique is a common method for fast assessment of dose rate over an extended territory in emergency situations. The measurements were conducted 3 times: on March 16, April 11 and April 25, 2011. The distance between Fukushima NPS and each measurement point was from 60 to $355 \mathrm{~km}$ and more than 100 measurements were obtained in each survey. The typical distance between measurement points were approximately $3 \mathrm{~km}$.
Shielding by the car body was estimated by making measurements inside and outside of the car at 56 points. A shielding factor $1.9 \pm 0.04$ was found. This was used for correction of the measured value as to represent outside dose rate. Moreover, the dose rates in air on pavement and on unsealed surfaces were compared.

In-situ gamma spectrometry. At several points in-situ gamma spectra were obtained using a $3^{\prime \prime} \times 3^{\prime \prime} \mathrm{NaI}(\mathrm{Tl})$ scintillation spectrometer (JSM-112, ALOKA Co., Japan). Measurements were carried out $1 \mathrm{~m}$ above the ground at each measurement site on March 19, and April 25. Counting time was set to $300 \mathrm{~s}$.

Car-borne survey within the high level contamination area. The car-borne survey within the high level contamination area was performed from April 11 to April 15, 2011. The survey route was selected after consideration of the database of MEXT ${ }^{9}$. In particular, a detailed survey was conducted in Iitate Village $\left(37.61^{\circ} \mathrm{N}, 140.75^{\circ} \mathrm{E}\right.$; $33 \mathrm{~km} \mathrm{NW}$ of the Fukushima NPS) and Namie Town $\left(37.60^{\circ} \mathrm{N}, 140.75^{\circ} \mathrm{E} ; 31 \mathrm{~km}\right.$ NW of the Fukushima NPS) which were in the high level dose area. The measurement technique was the same as in the expressway survey. 1623 measurements were performed. A contour mapping software "TOUKO" developed by the Radiation Earth Science Laboratory was used for this study. The measured values of Longitude, Latitude and dose rate were input to this software and a contour map was drawn by inverse distance weighted method $^{16}$.

1. Monateersky, R. Giant shock rattles ideas about quake behavior. Nature 471, 274 (2011).

2. Ozawa, S. et al. Coseismic and postseismic slip of the 2011 magnitude-9 TohokuOki earthquake. Nature 475, 373-376 (2011).

3. Tanimoto, T., Uchida, N., Kodama, Y., Teshima, T. \& Taniguchi, S. Safety of workers at the Fukushima Daiichi nuclear power plant. Lancet 377, 1489-1490 (2011).

4. Butler, C. Radioactivity spreads in Japan. Nature 471, 555-556 (2011).

5. Matsumura, H., Saito, K., Ishioka, J. \& Uwamino, Y. Behavior of radioactive materials from Fukushima Daiichi nuclear power station obtained by radiation san on the expressways. J. At. Energy Soc. Jpn. 10, 152-162 (2011).

6. Bowyer, T. W. et al. Elevated radioxenon detected remotely following the Fukushima nuclear accident. J. Environ. Radioact. 102, 681-687 (2011).

7. Manolopoulou, M., Vagena, E., Stoulos, S., Ioannidou, A. \& Papastefanou, C. Radioiodine and radiocesium in Thessaloniki, Northern Greece due to the Fukushima nuclear accident, J. Environ. Radioact. 102, 796-797 (2011).

8. Minato, S. Distribution of terrestrial $\gamma$ ray dose rates in Japan. J. Geography (Chigaku Zasshi) 115, 87-95 (2006).

9. Ministry of Education, Culture, Sports, Science and Technology Japan. http:// www.mext.go.jp/ (accessed 2011.6.23)

10. Minato, S. Evaluation of radioactivities released from the Fukushima Nuclear Power Plant by response matrix method. RESL Rep. SCS-0073, pp.1-8 (2011).

11. Halldin, S., Rodhe, A. \& Bjurman, B. Urban storm water transport and wash-off of cesium-137 after the Chernobyl accident. Water Air Soil Pollut. 49, 139-158 (1990).

12. Mueck, K. \& Steger, F. Wash-off effects in urban areas. Radiat. Prot. Dosim. 37, 189-194 (1991).

13. Garger, E. K. et al. Measurement of resuspended aerosol in the Chernobyl area I. Discussion of instrumentation and estimation of measurement uncertainty. Radiat. Environ. Biophys. 36, 139-148 (1997). 
14. Garger, E. K., Kashpur, V., Paretzke, H. G. \& Tschiersch, J. Measurement of resuspended aerosol in the Chernobyl area Part II. Size distribution of radioactive particles. Radiat. Environ. Biophys. 36, 275-283 (1998).

15. Fukushima Prefecture. http://www.pref.fukushima.jp/ (accessed 2011.6.7)

16. Franke, R. Scattered data interpolation: Test of some methods, Math. Comp. 38, 181-200 (1982).

\section{Acknowledgments}

This work was partly supported by a Grant for the Co-medical Education Program in Radiation Emergency Medicine by the Ministry of Education, Culture, Sports, Science and Technology, Japan (2011). The authors thank Prof. Yasushi Asari, Hirosaki University,

Prof. Michikuni Shimo, Fujita Health University and Dr. Susumu Minato, Radiation Earth Science Laboratory for their kind assistance in carrying out this study.

\section{Author contributions}

M.H., S.T. and I.K. designed the study; M.H., S.T., A.S., S.M., M.O., M.Y. and S.A. performed experiments; M.H. and S.T. wrote the manuscript; S.T. supervised the study. All authors contributed extensively to discussions about this work and in reviewing the manuscript.

\section{Additional information}

Competing financial interests: The authors declare no competing financial interests.

License: This work is licensed under a Creative Commons

Attribution-NonCommercial-ShareAlike 3.0 Unported License. To view a copy of this license, visit http://creativecommons.org/licenses/by-nc-sa/3.0/

How to cite this article: Hosoda, M. et al. The time variation of dose rate artificially increased by the Fukushima nuclear crisis. Sci. Rep. 1, 87; DOI:10.1038/srep00087 (2011). 